\title{
BMJ Open GPs' views on the implementation of combined lifestyle interventions in primary care in the Netherlands: a qualitative study
}

\author{
W van der Heiden (D) , ${ }^{1,2}$ JPW Lacroix, ${ }^{2}$ EP Moll van Charante, ${ }^{1,3}$ EJAJ Beune (D) ${ }^{1}$
}

To cite: van der Heiden W, Lacroix JPW, Moll van

Charante EP, et al. GPs' views on the implementation of combined lifestyle interventions in primary care in the Netherlands: a qualitative study. BMJ Open 2022;12:e056451. doi:10.1136/ bmjopen-2021-056451

- Prepublication history and additional supplemental material for this paper are available online. To view these files, please visit the journal online (http://dx.doi.org/10.1136/ bmjopen-2021-056451).

Received 01 September 2021 Accepted 11 January 2022

Check for updates

(c) Author(s) (or their employer(s)) 2022. Re-use permitted under CC BY-NC. No commercial re-use. See rights and permissions. Published by BMJ.

${ }^{1}$ Department of Public \& Occupational Health, Amsterdam UMC, University of Amsterdam, Amsterdam, Amsterdam Public Health Research Institute, Amsterdam, The Netherlands ${ }^{2}$ Department of Digital Engagement, Cognition and Behavior, Philips Research, Eindhoven, The Netherlands

${ }^{3}$ Department of General Practice, Amsterdam UMC, University of Amsterdam, Amsterdam, The Netherlands

Correspondence to

Dr. EJAJ Beune;

e.j.beune@amsterdamumc.nl

\section{ABSTRACT}

Objectives Prevention and lifestyle support are emerging topics in general practice. Healthcare insurance companies reimburse combined lifestyle interventions (CLIs) in the Netherlands since January 2019. CLIs support people with overweight (body mass index, BMI 25-30) or obesity $(\mathrm{BMI}>30)$ to reduce weight in peer groups. General practitioners (GPs) are key in the successful implementation of lifestyle interventions in primary care. This study explored GPs' experiences and views on the implementation of CLIs to identify barriers and facilitators to the successful implementation in primary care. Design Qualitative study using semistructured interviews. Content analysis consisted of thematic coding and mapping a first stage of predefined and second stage of iterative evolving set of themes.

Setting GPs were interviewed in a variety of primary care practices between February and April 2019.

Participants Fifteen GPs were purposively recruited for semi-structured interviews through snowballing.

Results Experiences with lifestyle support among GPs ranged from referring patients to other healthcare professionals to taking a proactive role in lifestyle support themselves. Whether or not GPs took an active role in lifestyle support was related to their belief in the effect of lifestyle interventions. Overall, GPs had little experience with CLI in every day practice. Perceived barriers were a lack of availability of CLIs in the region and the potential lack of added value of CLIs on top of existing lifestyle support. Perceived facilitators were coordination of care provision by GP cooperatives and monitoring of the CLI implementation and their results. Reimbursement of CLIs without any costs for participants enabled application. Conclusion The importance of lifestyle interventions in primary care was acknowledged by all GPs, but they differed in their level of experience with providing lifestyle support and awareness of CLIs. Successful integration of CLIs with primary care requires a solid promotion, a well-coordinated implementation strategy and structural evaluation of long-term effectiveness.

\section{INTRODUCTION}

Implementation of innovations in healthcare is often challenging. ${ }^{1}$ Even when evidence for a new intervention is present, the implementation takes years to be implemented. ${ }^{2}$
Strengths and limitations of this study

- Qualitative analysis of the first experiences and expectations of healthcare interventions at an early stage can provide valuable information on barriers and facilitators to implementation.

- This is the first study to explore how general practice initially responded to a new reimbursement policy regarding the combined lifestyle intervention (CLI) in the Netherlands.

- Interviews took place in a relatively early phase after the reimbursement policy started which allowed us to study initial responses to the introduction of the policy, even though overall perceptions of the general practitioners (GPs) may have changed over time due to more experience and more public discussion related to the CLIs.

- Only GPs were interviewed and the study results may therefore not be generalisable to perspectives of other health care workers or patients.

Implementation researchers have reported several factors that may positively or negatively influence implementation of innovations in healthcare. These factors can be divided into a number of domains: characteristics of the innovation itself, the organisation, the socio-political context, the available resources and the adopting individual. ${ }^{3-5}$ Moreover, successful implementation largely depends on the commitment and support of involved healthcare professionals. ${ }^{67}$ More insight into factors influencing the process of implementation can be achieved by studying specific implementation cases. ${ }^{8}$

Since January 2019, healthcare insurances in de Netherlands have started to reimburse combined lifestyle interventions (CLIs) for people with overweight or obesity. The CLI is reimbursed from basic health insurance when people have a body mass index (BMI) of: (1) 25-30 and have an increased risk of cardiovascular disease or type 2 diabetes, or (2) 30 or above. ${ }^{9}$ CLIs are multicomponent 
interventions, which consists of interactive sessions with care professionals (e.g., a lifestyle coach, practice nurse or a paramedic). The programme is tailored to the personal needs of the participants and includes group sessions to educate participants on certain topics, share experiences and provide support. ${ }^{10-12}$ Participants receive coaching on physical activity and healthy nutrition to achieve weight reduction. ${ }^{13} 14$ The intervention takes 2 years, because previous research has shown that a shorter intervention is often ineffective. ${ }^{15} 16$ While in the first year, much emphasis is on guided activities, including exercise, education and sharing experiences, the second year focusses more on self-management and sustaining lifestyle changes. Lifestyle coaches, trained at a certified educational institute, are accredited to deliver CLIs to patients referred by general practitioners (GPs).

GPs are increasingly confronted with people with unhealthy weight in their daily practice, with approximately a quarter of the world population being overweight and one-third of them being obese. ${ }^{17}$ Unhealthy weight is a major driver for chronic conditions such as diabetes and cardiovascular diseases, ${ }^{18}$ and contributes to poor quality of life and increased healthcare costs. ${ }^{19}$ Therefore, there is a growing urgency to address overweight or obesity by offering healthy lifestyle support in primary healthcare. ${ }^{20}$ In particular, multicomponent lifestyle interventions appear to be promising in effectively reducing overweight and obesity. ${ }^{21-27}$ Due to the new reimbursement policy for CLIs, all Dutch citizens with overweight or obesity became formally eligible for refunded participation in a CLI per January 2019.

One important but often overlooked question is whether healthcare innovations can be successfully implemented and scaled up in practice. This study explored GPs' experiences and views on the implementation of CLIs in primary care to identify barriers and facilitators to the successful implementation and scaling of healthcare innovations in primary care. Barriers and facilitators at an early stage of implementation were identified. This knowledge may contribute to optimising implementation of CLIs and/or similar healthcare innovations into primary care.

\section{METHODS}

\section{Study design}

This qualitative study consisted of semistructured interviews among a purposive sample of $15 \mathrm{GPs}$, guided by a topic list. The technology acceptance model (TAM) ${ }^{28}$ was used as inspiration and framework for relevant topics for the interview guide (table 1) and coding of the transcripts. The TAM model was chosen as this was originally developed as a framework for the introduction and implementation of innovative interventions. ${ }^{29}{ }^{30}$ Several TAM variations have been developed since the introduction of the original TAM, which have been proven useful in different research domains, including implementation research in healthcare. ${ }^{31}$

\begin{tabular}{|c|c|}
\hline Topics & \\
\hline $\begin{array}{l}\text { Introduction } \\
\text { researcher }\end{array}$ & $\begin{array}{l}\text { Introduction interviewer, research group } \\
\text { and sign informed consent }\end{array}$ \\
\hline $\begin{array}{l}\text { Introduction } \\
\text { participant }\end{array}$ & Characteristics of GP \\
\hline Prevention & Thoughts on role of GP in prevention \\
\hline $\begin{array}{l}\text { Lifestyle } \\
\text { interventions }\end{array}$ & View on lifestyle interventions \\
\hline CLIs & $\begin{array}{l}\text { Awareness and knowledge of CLIs, view } \\
\text { on CLls }\end{array}$ \\
\hline Experiences & $\begin{array}{l}\text { Experiences with lifestyle interventions, } \\
\text { lifestyle coaches and CLls }\end{array}$ \\
\hline Effectiveness & $\begin{array}{l}\text { Belief in effectiveness of CLIs, their } \\
\text { added value on current care provision }\end{array}$ \\
\hline Intention & $\begin{array}{l}\text { Intention of referring to CLI coaches, } \\
\text { benefit of reimbursement }\end{array}$ \\
\hline Implementation & $\begin{array}{l}\text { Facilitators and barriers for } \\
\text { implementation, ideal implementation }\end{array}$ \\
\hline $\begin{array}{l}\text { Feedback on } \\
\text { interview }\end{array}$ & $\begin{array}{l}\text { Feedback of participant on topics and } \\
\text { questions }\end{array}$ \\
\hline
\end{tabular}

CLIs, combined lifesyle interventions; GP, general practitioner.

\section{Setting}

In the Netherlands, more than $80 \%$ of GPs share a practice with other GPs. ${ }^{32}$ Most GPs work closely with practice nurses, who support them with the care for patients with a chronic condition within the general practice, for example, diabetes and cardiovascular diseases. Some of the general practices are part of a health centre, which are defined as multidisciplinary primary care practices with additional primary care providers (including practice nurses, physical therapists, dieticians, etc). In addition, general practices and/or health centres can be part of a care group, which are defined as local or regional GP networks, involved in shared contracts on chronic care delivery with health insurance companies. ${ }^{32}$

\section{Recruitment}

Fifteen GPs across a diversity of primary care practices were purposively recruited for semistructured interviews. Purposive sampling was used to enable balance for the following GP characteristics: gender (M/F), working experience $(0-10,>10$ years) type of general practice (healthcare centre: $\mathrm{Y} / \mathrm{N}$, part of care group: $\mathrm{Y} / \mathrm{N}$ ). Recruitment of GPs took place through snowballing, covering a large geographical area of the Netherlands to ensure sufficient contrasts. Invitations were sent by email, followed by an information letter after a positive reply. The interviews took place between February and April 2019. Overall, 15 GPs took part in an interview. In line with the Amsterdam UMC code of good conduct in medical research, ${ }^{33}$ provisions were made to assure the anonymity of the respondents in data collection, analysis and presentation. 


\section{Data collection}

All interviews were conducted face to face at the GP practice by $\mathrm{WvdH}$, a medical student in the final phase of training. The interviews lasted about half an hour on average. The researcher verified whether the participant had read the information letter, before asking for written consent. All interviews were audiorecorded with participants' permission. After interim analysis based on half of the interviews, one topic was added to the interview guide, to obtain a deeper understanding what constitutes optimal implementation of CLIs in daily practice. To increase content validity, the GPs were asked for feedback after each interview, about the relevance of the research questions and suggestions for additional questions. The input was used to make further adjustments to wording and sequencing of the topic guide for subsequent interviews. GPs received a small reimbursement (gift voucher) for their participation. Since most of them were relatively unfamiliar with the CLI, two additional GPs who gained clear experience with the CLI were recruited and interviewed. The research team read all (WvdH and JL) or a subset of the coded transcripts (EMvC and EB), discussed them among the team members and established the level of data saturation, based on the results of new interviews in relation to the previous findings. Thematic saturation ${ }^{34}$ occurred after 15 interviews.

\section{Data analysis}

The framework method for qualitative research was followed for a systematic approach of data analysis. ${ }^{35}$ This comprised the stages of transcription, familiarisation, coding, applying the framework and interpretation. All but one of the interviews were transcribed verbatim. One audio recording failed due to a technical error. Instead of being transcribed, $\mathrm{WvdH}$ summarised the conversation immediately after the interview. Familiarisation with the data took place during transcription and by reading the transcripts in detail. In parallel, the interview guide was discussed and refined by the research team. Transcripts were coded using both an inductive and deductive approach with supporting qualitative data analysis software ATLAS.ti $8 .^{36}$ Two separate researchers (WvdH and JL) coded the transcripts, starting with an inductive open coding phase, identifying categories and applying a code to a line or paragraph. After the first three transcripts, these open codes were deductively assigned to the categories of the TAM model. ${ }^{28}$ Applied categories were perceived utility, perceived ease of use and intention to use, including their subcategories, creating a coding scheme. When a code did not fit TAM the model, a new category was created, capturing the essence of the code. After the full research team agreed on the identified categories and codes, the final coding scheme emerged, which then was applied on all transcripts. The Standards for

\begin{tabular}{ll}
\hline Table 2 Themes and subthemes in results \\
\hline Themes & Subthemes \\
\hline $\begin{array}{l}\text { Relevance and use of } \\
\text { lifestyle interventions in } \\
\text { general }\end{array}$ & $\begin{array}{l}\text { GPs' role in lifestyle } \\
\text { modification interventions } \\
\text { Perceived effectiveness of } \\
\text { lifestyle interventions }\end{array}$ \\
$\begin{array}{l}\text { Relevance and use } \\
\text { of combined lifestyle } \\
\text { interventions (CLIs) }\end{array}$ & $\begin{array}{l}\text { Awareness of CLI } \\
\text { Perceived effectiveness of CLI } \\
\text { Barriers and facilitators to } \\
\text { implementation of CLIs }\end{array}$ \\
\hline
\end{tabular}

CLIs, combined lifesyle interventions; GPs, general practitioners.

Reporting Qualitative Research were used as guideline for appropriate reporting. ${ }^{37}$

\section{Patient and public involvement}

There was no patient or public involvement in the study.

\section{RESULTS}

\section{Sample of GPs}

The purposive sample of GPs contained a balance in the intended characteristics (online supplemental appendix 1). The experience with referring patients to CLIs (hardly any experience/little experience/ experienced) emerged during data analysis, to be clearly related with GPs' view on lifestyle interventions and potential barriers and facilitators. Therefore, the research team decided to include this characteristic as an additional sampling criterion.

\section{Perceptions, intentions and behaviour of GPs}

The perception, intentions and behaviour of GPs regarding the implementation of CLIs in primary care could be categorised into three main themes: (1) Relevance and use of lifestyle interventions in general, (2) Relevance and use of CLIs and (3) Barriers and facilitators to the implementation of CLIs. Each theme will be discussed below, with the corresponding subthemes, as summarised in table 2.

\section{Relevance and use of lifestyle interventions in general}

GPs' views on the relevance of lifestyle interventions and their current use in daily practice was influenced by their opinion about the role a GP should play in lifestyle support as well as the perceived effectiveness of lifestyle interventions.

\section{GPs' role in lifestyle modification interventions}

Prevention through lifestyle interventions was considered important by all GPs, although there was substantial variation on perceived relevance and the role of the GP in lifestyle interventions.

From the interviews, two main approaches of lifestyle support by GPs emerged. The first one focused on 
referral of eligible patients to qualified professionals for further lifestyle coaching.

When you want to do something with lifestyle, you often refer to the dietician or physical therapist for example. Nowadays, it's often embedded in a chronic care program, such as the one for diabetes. - GP 7, Male

The second approach was followed by GPs taking an active role in guidance on healthy lifestyles themselves.

I actually experiment with lifestyle support myself, for example by doing a onehour lifestyle consultation, to discuss all kinds of lifestyle-related issues in more detail. I am busy with all kinds of projects, together with social work, physiotherapists, dieticians and lifestyle coach-like people, from which a nice network has emerged. - GP 2, Male

One of the interviewees believed achieving a healthy lifestyle was a responsibility that primarily lied with patients themselves, without the need to provide largescale support and coaching.

I think the best thing is if patients take control themselves. Without the help of other care providers (besides GPs), becoming more independent and stronger and taking it into their own hands. - GP 3, Male

Next to their own role, GPs felt that the national government plays an important role in prevention, mainly through policies and regulations promoting a healthy lifestyle, for example, raising taxes on unhealthy food products.

I think the government has a big role in imposing taxes and other smart things. How products are displayed in the supermarket, the locations of snack bars... instead of leaving it up to the medical care. - GP 13, Male

GPs' own experiences with providing or referring their patients for lifestyle support appeared to have a positive effect on their judgement of this type of care provision, due to the stimulating effect of ample positive feedback from their patients and the health results that were achieved.

You see that people can get rid of their medication, that HbA1c has gone down, that blood pressure is improving, that people are losing weight, that kind of things. That shows me that it is effective. - GP 2, Male

\section{Perceived effectiveness of lifestyle interventions}

One of the main factors driving the judgement on lifestyle programmes was the GP's perceived effectiveness of these interventions with quality of the lifestyle coaches and intensity (duration and number of sessions) playing a big role.

It obviously depends on the intervention, how many contact moments there are for communication and weighing. Besides that, when such a program ends, are people left to themselves again or do they still have follow-up meetings regularly? Of course, we know from research that behaviour change takes time. If it is a very short intervention without any follow-up, it is not going to be effective. - GP 1, Female

Patient's motivation also was an important prerequisite for effectiveness of lifestyle interventions. Most GPs considered it their responsibility to motivate participants, but some felt that without a certain motivation level any attempt would be useless.

Lifestyle interventions can be extremely effective in risk reduction. However, that definitely requires patient's motivation. Unfortunately, many think it will be arranged for them if they start with something like that (CLI). Of course, that's not the case. You get information, you get advice, you get a helping hand, but in the end, you have to do it yourself. - GP 15, Female

Both, a proactive attitude of GPs in offering lifestyle support and more experience with lifestyle interventions, made GPs more convinced of the potential effectiveness and usefulness of lifestyle interventions in general.

\section{Relevance and use of CLIs}

Only few GPs were well aware of the recently introduced CLI-programmes and almost no one had experience with referring patients to a CLI. The perceived effectiveness of CLIs varied.

\section{Awareness of CLI}

Only few GPs appeared to be well informed on the concept of a certified coach and lifestyle groups for weight reduction for obese patients with high cardiovascular risk profile. GPs indicated that more understanding of the proposed multicomponent interventions was necessary to facilitate their referral of patients to such programmes.

I need to know more about it (CLI) and have clearer and more specific information about it... I think if I know more about it, someone explains me more clearly what will be reimbursed or not, what the investment is for the patient, what happens if they drop out, then I might be able to do something with it. - GP 10, Male

The interviews revealed that GPs had a more positive attitude towards the programme when they had an unequivocal understanding for which of their patients CLI was intended, as it was not always clear which patients were eligible for participation in CLIs.

I do have a number of patients in mind who are overweight or obese and if the CLI might be a solution for them, that would be great. - GP 7, Male

\section{Perceived effectiveness of CLI}

Some GPs believed CLIs could be effective in the prevention of chronic diseases.

I think something like that (CLI) is much better than all those pills we prescribe. These are the things that have been 
proven to be good for you, if you exercise it is good for the prevention of cardiovascular disease, for diabetes, it is good for everything. - GP 9, Female

However, some were sceptical about the added value of such interventions above and beyond the already well-established support offered by existing qualified paramedical healthcare professionals, such as physiotherapists, dieticians or practice nurses. GPs without prior experience with CLI felt that the introduction of a lifestyle coach might even complicate referral procedures.

Do I believe in it (lifestyle coach)? Well, I am not convinced yet. A lifestyle coach is a new profession in healthcare. What is their background, what can they do? I think you can easily call yourself a lifestyle coach. When I will co-operate with someone, I need to have a little bit of faith in someone. I want to know that someone can actually do what is asked.

- GP4, Female

Finally, GPs often expressed doubts on the long-term effect of CLIs, despite a potential beneficial short-term effect in behavioural change.

I'm always a little afraid of a temporary effect only. After 2 years, that (CLI) is stopped and then people can easily fall back into old behavioural patterns. That is the problem with groups, as long as they are together, it is going well, but I think it is very difficult to maintain the lifestyle changes afterwards. - GP 4, Female

\section{Experiences with CLI}

The four GPs who had gained some experience with CLIs and lifestyle coaches worked within care groups which had contracted this type of care.

We refer people with cardiovascular diseases to lifestyle groups and recently we have also started referring overweight people to the combined lifestyle intervention. - GP 15, Female

All of them were positive on the group sessions being part of the CLIs and were convinced of the added value of these group sessions on current lifestyle care.

It's nice to hear the experiences of other people, to hear those others struggle with the same problems. Sometimes people get to know each other, pick things up together, have each other's support. So, I think it is certainly not for everyone, but it is very useful for quite a lot of people. - GP 14, Female

Limited awareness of CLIs among GPs and lack of belief in the long-term effect or the added value of CLIs-on top of established interventions-may result in barriers for the implementation of CLIs. On the contrary, GPs who are convinced CLIs may be effective and who have a positive experience, may contribute successful implementation of CLIs.

\section{Barriers and facilitators to implementation of CLls}

The interviews revealed several factors that may affect successful implementation of CLI.
Barriers

Most GPs indicated already providing lifestyle advice on a daily basis and therefore were not always convinced that CLIs would have an additional value.

In all honesty, I think prevention is always a complicated issue in general practice. We're busy with prevention all day long, giving lifestyle advice throughout the day. That is what I also think with this CLI, it is what we are already doing all the time, isn't it? What more can we offer? - GP 5, Female

The limited budget health insurance companies received from the government was seen as a major barrier for CLI implementation, yielding insufficient room to cover the eligible high-risk population within their practice population.

\section{It (CLI) will not get off the ground, because they have delib- erately limited the budget. - GP 13, Male}

Lack of convincing scientific evidence on the effectiveness of the CLI for the patient was also mentioned as a barrier to implementation. Therefore, GPs proposed to test CLIs in a trial first, before the government would take a final decision on large-scale funding of such programmes in the healthcare landscape. Finally, lack of visibility of CLI-offering organisations in the close vicinity of the practice, as well as shortage of certified lifestyle coaches were mentioned as barriers to make use of CLIs.

\section{Facilitators}

GPs indicated that successful implementation of CLIs would mainly depend on long-term financial and organisational support.

I hope that when health insurance companies say we will reimburse it, they will do so for at least 5 years or so. That there is the opportunity to build something and have success with it. Because I think, it takes around 2-3 years before such a new measure is picked up a bit. - GP 1, Female

Other prerequisites for a successful programme were adequate, centralised coordination of the implementation, and continuous monitoring and evaluation of the programme with key stakeholders, including GPs.

We have a regional primary care organization for the entire region, so to speak. Almost all general practitioners are affiliated with it. They are responsible for the organisation of chronic care, people with cardiovascular disease, diabetes and COPD for example. This (CLIs) is actually part of it, so the organization will pick it up and inform us (GPS) on it. - GP 12, Female

This preference was emphasised by the GPs who had already worked with CLIs.

You need someone who takes care of the organisation. A GP cooperative is quite an appropriate organisation for that, $I$ think. Someone who examines: do we have lifestyle coaches in the region, how are we going to get more, how are we going to arrange referrals from general practitioners to lifestyle 
coaches and how do we ensure that they become known to general practitioners? - GP 14, Female

\section{DISCUSSION}

\section{Main findings}

In this study, we explored GPs' views on the implementation of CLIs in primary care, from an early moment of the introduction of the reimbursement policy in the Netherlands. Most GPs acknowledge the relevance and importance of lifestyle support across a broad spectrum of patients. GPs' views on lifestyle support programmes were influenced by their belief in its effectiveness and their perceived professional role in preventive care. In addition, this appeared to be closely related to the way they put personal lifestyle guidance into practice, or to referrals to healthcare professionals to deliver such care, including CLI coaches. According to GPs, the implementation of CLIs fell short on several levels. First, there was limited awareness of CLIs among GPs, and also the content of the CLIs and its effectiveness was not entirely clear. GPs were not always convinced of the added value of such programmes above and beyond the existing lifestyle support already offered by paramedical professionals (e.g., physiotherapists, dieticians). Most GPs indicated they provided lifestyle support on a daily basis themselves. Second, the amount of available budget for CLI reimbursement was perceived to be insufficient to cover the costs of the entire group of eligible patients. The CLI reimbursement policy was also perceived as a potential threat to other, already established, healthcare professions and lifestyle interventions. Third, limited capacity of CLI coaches in the proximity of the GP practice, as well as a lack of coordination of the implementation of CLI programmes was regarded as a potential barrier to their adoption. According to the GPs, a well-coordinated introduction of CLIs for GP practices would facilitate early adoption and implementation. GPs also indicated that continuous monitoring and evaluation of the CLI programme should be available, to create an evidence base on the long-term effectiveness. This is needed to justify and facilitate the allocation of sufficient budget for reimbursement of CLIs for all potentially eligible participants.

\section{Related work}

Below we discuss how the main findings relate to earlier work in this domain.

Previous implementation research has shown that GPs have different perceptions on whether lifestyle support is part of their core tasks. ${ }^{38-40}$ This is in line with our findings, showing a broad range of preferred strategies, from provision of personalised, active lifestyle support to referral of patients to other healthcare professionals. A crucial prerequisite for adopting preventive interventions, including lifestyle guidance, appears GPs' belief in their effectiveness. ${ }^{38} 41$ Conversely, the perceived lack of scientific evidence for their (long-term) effectiveness, or belief that healthcare authorities are better equipped to provide preventive care withholds GPs to implement interventions in practice. ${ }^{21} 384042-45$

Our study demonstrated a lack of awareness among GPs on the CLI and the reimbursement policy. Sufficient awareness and knowledge among GPs on content and effectiveness of new programmes appear to be important requirements for a positive attitude towards healthcare innovations. ${ }^{38} 46-48$ The visibility and sustained provision of behavioural lifestyle interventions is an additional factor that affects GPs' willingness to use them in their daily care. ${ }^{49}$ This appears to be strengthened by GPs' mention of their unfamiliarity with the CLI-programme's content and lifestyle coaches' new and unknown role as important barriers to its implementation. There is some evidence that education and early involvement of key stakeholders (e.g., those needed to implement the innovation) increase the adoption of healthcare innovations. ${ }^{43} 4650-53$ Facilitating increased awareness and knowledge on CLIs among GPs through actively involving GPs in an early phase could therefore contribute to their overall implementation.

Other factors that may impede implementation of behavioural lifestyle support programmes are high workload, lack of time and lack of finances. ${ }^{38-40} 4346$ In our study, burden of work or time constraints were hardly mentioned, possibly since the intervention mostly lay outside GPs' care provision. Nevertheless, they did raise concerns about potential limitations in funding and professional resources, which have been shown important factors for successful adoption. ${ }^{54}$ On the other hand, it was emphasised that coordination at the GP cooperative level was a clear potential facilitator for early adoption and implementation of the CLI.

\section{Strengths and limitations}

The timing of this study was at an opportune moment, as an intervention for primary care became available in real life, in order to observe to what extent a new policy was being leveraged. This made it possible to explore and understand facilitators and barriers for adoption in an early stage of implementation. These first experiences and expectations can inform the guidance of the further development of its implementation. However, this may also be a limitation, as overall perceptions of the GPs may have changed over time due to more experience and more public discussion related to the CLIs. Another limitation of our study is that it focused on GP's perspectives only, while the views of other stakeholders, including patients, health insurance companies or lifestyle coaches, could have led to more comprehensive insights on the dynamics of CLI implementation.

\section{CONCLUSION AND IMPLICATIONS}

This study showed that the early adoption and implementation of CLIs in primary care in the Netherlands 
is challenging. Although GPs acknowledged the importance of lifestyle support in general, the awareness of CLIs was still limited. At the same time, doubts about their effectiveness for participants, their added value on top of already existing lifestyle support interventions and the lack of resources for GPs to realise the CLI in practice, hindered their adoption. Policy makers, together with the developers of the CLIs, should pay attention to the adequate promotion of new CLIs and the early involvement of key stakeholders in the regional implementation. In addition, the available financial and professional resources to realise the CLI in practice for the entire group of potentially eligible people and coordination at a GP cooperative level must also be considered. Finally, attention should also be paid to the alignment with existing programmes for lifestyle support and preventive services in primary care and the feedback to the GPs on achieved results by participants. Proper monitoring and evaluation of the implementation of CLIs and their effectiveness may elucidate opportunities for improvement.

Acknowledgements The authors gratefully acknowledge all the GPs who shared their experiences and insights in order that we could understand to what extent a new policy regarding the CLIs in the Netherlands was being leveraged.

Contributors $\mathrm{WvdH}$ designed the study in collaboration with the research team, created the interview guide, led the qualitative data collection and conducted and transcribed the interviews, then coded all transcripts and has analysed the data in collaboration with the research team. JL assisted in the study design, recruited participants, finetuned the interview guide, coded transcripts and contributed to the interpretation of data and editing of the article. EMvC assisted in the study design, recruited participants, coded transcripts and contributed to the interpretation of data and editing of the article. EB assisted in the study design, recruited participants, coded transcripts and contributed to the interpretation of data and editing of the article. EB is responsible for the overall content as the guarantor. All authors provided feedback on the manuscript and approval to the publishing of this manuscript.

\section{Competing interests None declared.}

\section{Patient consent for publication Not applicable.}

Ethics approval The medical ethics committee of the Amsterdam UMC (location AMC) granted a waiver for this study (reference number NL68852.018.19). In line with Dutch legislation, this committee ruled that the study did not require extensive ethical review as participants were recruited on a volunteer basis and were not requested to undergo any physical examination or intervention.

Provenance and peer review Not commissioned; externally peer reviewed.

Data availability statement Data are available on reasonable request. The data are stored in a secure environment of the Amsterdam UMC. If necessary, data can be requested from EB (Department of Public and Occupational Health, Amsterdam UMC location AMC, Meibergdreef 15, 1105 AZ Amsterdam, e.j.beune@ amsterdamumc.nl).

Supplemental material This content has been supplied by the author(s). It has not been vetted by BMJ Publishing Group Limited (BMJ) and may not have been peer-reviewed. Any opinions or recommendations discussed are solely those of the author(s) and are not endorsed by BMJ. BMJ disclaims all liability and responsibility arising from any reliance placed on the content. Where the content includes any translated material, BMJ does not warrant the accuracy and reliability of the translations (including but not limited to local regulations, clinical guidelines, terminology, drug names and drug dosages), and is not responsible for any error and/or omissions arising from translation and adaptation or otherwise.

Open access This is an open access article distributed in accordance with the Creative Commons Attribution Non Commercial (CC BY-NC 4.0) license, which permits others to distribute, remix, adapt, build upon this work non-commercially, and license their derivative works on different terms, provided the original work is properly cited, appropriate credit is given, any changes made indicated, and the use is non-commercial. See: http://creativecommons.org/licenses/by-nc/4.0/.

\section{ORCID iDs}

W van der Heiden http://orcid.org/0000-0003-1076-7371

EJAJ Beune http://orcid.org/0000-0002-6229-0256

\section{REFERENCES}

1 Barnett J, Vasileiou K, Djemil F, et al. Understanding innovators experiences of barriers and facilitators in implementation and diffusion of healthcare service innovations: a qualitative study. BMC Health Serv Res 2011;11:342.

2 Berwick DM. Disseminating innovations in health care. JAMA 2003;289:1969-75.

3 Michie S, Johnston M, Abraham C, et al. Making psychological theory useful for implementing evidence based practice: a consensus approach. Qual Saf Health Care 2005;14:26-33.

4 Fleuren MAH, Paulussen TGWM, Van Dommelen P, et al. Towards a measurement instrument for determinants of innovations. Int J Qual Health Care 2014;26:501-10.

5 Fleuren M, Wiefferink K, Paulussen T. Determinants of innovation within health care organizations. Int J Qual Heal Care 2004:16:107-23.

6 Teuscher D, Bukman AJ, Van BMA, et al. A lifestyle intervention study targeting individuals with low socioeconomic status of different ethnic origins : important aspects for successful implementation 2018:1-10.

7 Fischer F, Lange K, Klose K, et al. Barriers and strategies in guideline Implementation-A scoping review. Health Care 2016;4:36.

8 Peters DH, Adam T, Alonge O. Implementation research : what it is and how to do it 2013;6753:1-7.

9 Rijksinstituut voor Volksgezondheid en Milieu (RIVM). Factsheet gecombineerde leefstijl interventie.

10 Huis voor Beweging. Beschrijving interventie BeweegKuur. RIVM 2015.

11 Expertisecentrum Leefstijlinterventies. Beschrijving interventie CooL. RIVM 2015

12 GGD Noord- en Oost-Gelderland. Beschrijving interventie SLIMMER. RIVM 2015

13 Berendsen BAJ, Hendriks MRC, Rutten GM, et al. The added value of frequent physical activity group sessions in a combined lifestyle intervention: a cluster randomised trial in primary care. Prev Med Rep 2020;20:101204.

14 Gremeaux V, Drigny J, Nigam A, et al. Long-term lifestyle intervention with optimized high-intensity interval training improves body composition, cardiometabolic risk, and exercise parameters in patients with abdominal obesity. Am J Phys Med Rehabil 2012;91:941-50.

15 Peiris CL, Taylor NF, Hull S, et al. A group lifestyle intervention program is associated with reduced emergency department presentations for people with metabolic syndrome: a retrospective case-control study. Metab Syndr Relat Disord 2018;16:110-6.

16 Hardcastle S, Taylor A, Bailey M, et al. A randomised controlled trial on the effectiveness of a primary health care based counselling intervention on physical activity, diet and CHD risk factors. Patient Educ Couns 2008;70:31-9.

17 Seidell JC, Halberstadt J. The global burden of obesity and the challenges of prevention. Ann Nutr Metab 2015;66(Suppl 2):7-12.

18 World Health Organization. 10 facts on obesity, 2017.

19 World Health Organization. Global health expenditure database 2016

20 Lee I-M, Shiroma EJ, Lobelo F, et al. Effect of physical inactivity on major non-communicable diseases worldwide: an analysis of burden of disease and life expectancy. Lancet 2012;380:219-29.

21 Mai K, Brachs M, Leupelt V, et al. Effects of a combined dietary, exercise and behavioral intervention and sympathetic system on body weight maintenance after intended weight loss: results of a randomized controlled trial. Metabolism 2018;83:60-7.

22 König D, Hörmann J, Predel H-G, et al. A 12-month lifestyle intervention program improves body composition and reduces the prevalence of prediabetes in obese patients. Obes Facts 2018;11:393-9.

23 Hassan Y, Head V, Jacob D, et al. Lifestyle interventions for weight loss in adults with severe obesity: a systematic review. Clin Obes 2016;6:395-403.

24 Duijzer G, Haveman-Nies A, Jansen SC, et al. Effect and maintenance of the SLIMMER diabetes prevention lifestyle intervention in Dutch primary healthcare: a randomised controlled trial. Nutr Diabetes 2017;7:e268. 
25 Roumen C, Blaak EE, Corpeleijn E. Lifestyle intervention for prevention of diabetes: determinants of success for future implementation. Nutr Rev 2009;67:132-46.

26 Schutte BAM, Haveman-Nies A, Preller L. One-year results of the BeweegKuur lifestyle intervention implemented in Dutch primary healthcare settings. Biomed Res Int 2015;2015:1-7.

27 Zhang Y, Pan X-F, Chen J, et al. Combined lifestyle factors and risk of incident type 2 diabetes and prognosis among individuals with type 2 diabetes: a systematic review and meta-analysis of prospective cohort studies. Diabetologia 2020;63:21-33.

28 Venkatesh V, Davis FD. A theoretical extension of the technology acceptance model: four longitudinal field studies. Manage $\mathrm{Sci}$ 2000;46:186-204.

29 Davis FD. Perceived usefulness, perceived ease of use, and user acceptance of information technology. MIS Quarterly 1989;13:319-40.

30 Davis FD, Bagozzi RP, Warshaw PR. User acceptance of computer technology: a comparison of two theoretical models. Manage Sci 1989;35:982-1003.

31 Holden RJ, Karsh B-T. The technology acceptance model: its past and its future in health care. J Biomed Inform 2010;43:159-72.

32 Tikkanen Ret al. International Health Care System Profiles Netherlands. Journal of the American Board of Family Medicine. 2020;6.

33 Independence in scientific research: research code AMC-VUmc 2019.

34 Saunders B, Sim J, Kingstone T, et al. Saturation in qualitative research: exploring its conceptualization and operationalization. Qual Quant 2018;52:1893-907.

35 Gale NK, Heath G, Cameron E, et al. Using the framework method for the analysis of qualitative data in multi-disciplinary health research. BMC Med Res Methodol 2013;13:117.

36 ATLAS.ti 8. p. Available: https://atlasti.com/

37 O'Brien BC, Harris IB, Beckman TJ, et al. Standards for reporting qualitative research: a synthesis of recommendations. Acad Med 2014;89:1245-51.

38 Geense WW, van de Glind IM, Visscher TLS, et al. Barriers, facilitators and attitudes influencing health promotion activities in general practice: an explorative pilot study. BMC Fam Pract 2013;14:20.

39 Ampt AJ, Amoroso C, Harris MF, et al. Attitudes, norms and controls influencing lifestyle risk factor management in general practice. BMC Fam Pract 2009;10:1-8.

40 Rubio-Valera M, Pons-Vigués M, Martínez-Andrés M, et al. Barriers and facilitators for the implementation of primary prevention and health promotion activities in primary care: a synthesis through metaethnography. PLoS One 2014;9:e89554.

41 Jansink R, Braspenning J, van der Weijden T, et al. Primary care nurses struggle with lifestyle counseling in diabetes care: a qualitative analysis. BMC Fam Pract 2010;11:41.
42 Sebo P, Maisonneuve H, Fournier J-P, et al. General practitioners views and preferences about quality improvement feedback in preventive care: a cross-sectional study in Switzerland and France. Implement Sci 2017;12:95.

43 Brotons C, Björkelund C, Bulc M, et al. Prevention and health promotion in clinical practice: the views of general practitioners in Europe. Prev Med 2005;40:595-601.

44 Verberne LDM, Hendriks MRC, Rutten GM, et al. Evaluation of a combined lifestyle intervention for overweight and obese patients in primary health care: a quasi-experimental design. Fam Pract 2016;33:671-7.

45 Haw JS, Galaviz KI, Straus AN, et al. Long-term sustainability of diabetes prevention approaches: a systematic review and meta-analysis of randomized clinical trials. JAMA Intern Med 2017:177:1808-17.

46 Molema CCM, Wendel-Vos GCW, ter Schegget S, et al. Perceived barriers and facilitators of the implementation of a combined lifestyle intervention with a financial incentive for chronically ill patients. BMC Fam Pract 2019;20:1-11.

47 Alayli A, Krebs F, Lorenz L, et al. Evaluation of a computer-assisted multi-professional intervention to address lifestyle-related risk factors for overweight and obesity in expecting mothers and their infants: protocol for an effectiveness-implementation hybrid study. BMC Public Health 2020;20:1-13.

48 Helmink JHM, Kremers SPJ, van Boekel LC, et al. Factors determining the motivation of primary health care professionals to implement and continue the 'Beweegkuur' lifestyle intervention programme. J Eval Clin Pract 2012;18:682-8.

49 Cohen Rodrigues TR, de Buisonjé DR, Keesman M, et al. Facilitators of and barriers to lifestyle support and eHealth solutions: interview study among health care professionals working in cardiac care. $J$ Med Internet Res 2021;23:e25646.

50 Grol R, Grimshaw J. From best evidence to best practice : effective implementation of change in patients ' care. Res into Pract 2003;362:1225-30.

51 Beune EJAJ, Haafkens JA, Bindels PJE. Barriers and enablers in the implementation of a provider-based intervention to stimulate culturally appropriate hypertension education. Patient Educ Couns 2011;82:74-80.

52 Kingma AEC, van Stel HF, Oudega R, et al. Multi-faceted implementation strategy to increase use of a clinical guideline for the diagnosis of deep venous thrombosis in primary care. Fam Pract 2017;34:446-51.

53 van Rinsum C, Gerards S, Rutten G, et al. The implementation of the coaching on lifestyle (CooL) intervention: lessons learnt. BMC Health Serv Res 2019;19:1-12.

54 Laws RA, Kemp LA, Harris MF, et al. An exploration of how clinician attitudes and beliefs influence the implementation of lifestyle risk factor management in primary healthcare: a grounded theory study. Implementation Sci 2009;4:1-15. 